\title{
Influence of aerobic exercise training on left ventricular remodeling and neurohumoral response in patients with myocardial infarction
}

\author{
Giovani Luiz De Santi*, Eduardo Elias Vieira de Carvalho, Daniela Caetano Costa, Júlio César Crescêncio, André Schmidt, José Antonio \\ Marin-Neto and Lourenço Gallo Júnior
}

Division of Cardiology, Medical School of Ribeirao Preto, University of Sao Paulo, Brazil

\begin{abstract}
Purpose: The effects of aerobic training on ventricular remodeling (VR) and neurohumoral activation after myocardial infarction (MI) have not been completely elucidated. It was investigated the influence of aerobic training on physical fitness, on VR and neurohumoral response after MI.

Methods: Sixteen patients with anterior wall myocardial infarction were randomized into two groups: training (TG=8) and control (CG=8). TG patients performed moderate-intensity aerobic training. Before and after a 12-week follow-up all patients underwent cardiac magnetic resonance, cardiopulmonary exercise testing and blood sampling for measurement of NT-proBNP.

Results: In the follow-up, there was a significant increase in the $\Delta \mathrm{O} 2$ pulse in the TG $(6.4 \pm 1.2$ to $8.1 \pm 1.7$; $\mathrm{p}=0.01)$, with no significant change in the CG (7.0 \pm 2.3 to $6.9 \pm 3.0 ; p>0.99$ ). It was observed an increase of LV mass/EDV ratio from $0.72 \pm 0.19$ to $0.96 \pm 0.30$ g.ml- 1 ( $p=0.007$ ) in the CG, but no change in the TG from $0.89 \pm 0.33$ to $0.96 \pm 0.26$ g.ml-1 $(\mathrm{p}=0.54)$. There was a significant decrease of NT-proBNP at rest and at effort peak in both groups.

Conclusion: Aerobic training seems to have a protective effect over the spontaneous process of LV concentric remodeling after myocardial infarction, and it promotes an improvement of the LV systolic performance during dynamic physical effort, without triggering adverse neurohumoral activation.
\end{abstract}

\section{Introduction}

Ventricular remodeling (VR) is the main determinant of the clinical course of asymptomatic ventricular dysfunction and subsequent heart failure. Some VR patterns appear to be adaptive and physiological, while others are associated with adverse cardiovascular events. Data available in the literature suggest that VR is an accurate predictor of mortality in the context of post-myocardial infarction (MI). [1-3] Therapeutic interventions aim to diminish or even reverse structural changes on cardiac architecture as a result of VR. In this sense, blocking of neurohumoral activation represents the cornerstone of therapy to minimize the process of VR, and modify the natural history of heart failure [4-6]. There is a substantial body of evidence documenting global improvement and decreased mortality related to physical exercise in the context of post-myocardial infarction. However, scientific research to assess the effects of physical exercise in the process of VR in patients with anterior wall MI and ventricular dysfunction, showed controversial results [7-9].

Under this perspective, it was investigated the influence of aerobic exercise training on physical and cardiorespiratory fitness, VR, and neurohumoral response of patients with anterior wall MI and asymptomatic ventricular dysfunction.

\section{Methods}

\section{Patients}

For this study, 16 patients with mean age of $54.6 \pm 10.5$ years, admitted to the Emergency Unit of General Hospital of Medical School of Ribeirao Preto of University of Sao Paulo for treatment of MI, were prospectively selected and evaluated between the $5^{\text {th }}$ and $24^{\text {th }}$ weeks after MI. They were randomly divided into two groups: training group (TG) and control group (CG). The two groups did not show statistically significant differences related to age, anthropometric characteristics, and elapsed time from MI, at the moment of inclusion in the study (Table 1). Prospectively established inclusion criteria were: anterior wall MI, univascular coronary disease involving exclusively the proximal part of the left anterior descending artery and asymptomatic ventricular dysfunction, with left ventricular (LV) ejection fraction $(\mathrm{EF})<45 \%$ evaluated by cardiac magnetic resonance. Exclusion criteria were the development of symptoms of heart failure, sustained ventricular tachycardia, chronic obstructive pulmonary disease, chronic renal failure, contraindications to medications routinely used as anti-VR medication, and orthopedic and/or neurological limitations that would prevent the implementation of physical exercise training.

During the acute MI, seven patients were maintained on clinical treatment without reperfusion therapy because they were not eligible at

Correspondence to: Giovani Luiz De Santi, Division of Cardiology, Medical School of Ribeirao Preto, University of Sao Paulo, Av. Bandeirantes, n 3.900, Ribeirao Preto-SP, Brazil, Zip: 14048-900; Tel: +551636022599, +551636022782, +553498020315; Fax: +551636021504; E-mail: giovanidesanti@usp.br

Key words: myocardial infarction, ventricular remodeling, neurohumoral activation, aerobic exercise training, cardiac resonance imaging

Received: February 15, 2017; Accepted: March 06, 2017; Published: March 08 2017 
the time of admission for fibrinolytic therapy or primary percutaneous coronary intervention. Seven patients received fibrinolytic therapy by intravenous administration of alteplase or tenecteplase. Two patients were treated with primary percutaneous coronary intervention (Table 1). All patients underwent during the hospital admission cardiac catheterization and percutaneous coronary intervention for the obstructed left anterior descending coronary artery. At the end of the procedure angiography of the infarct-related artery showed epicardial coronary flow TIMI 3 in all patients included in this study.

From an ethical point of view a rehabilitation program could be considered mandatory for all patients after an acute MI. The CG of our study was composed of patients not willing to engage in the regular exercise training program offered, but agreed to perform the subsequent reevaluation as required in the study protocol. The TG was composed by those patients who engaged in the complete training program.

Patients in both groups were maintained throughout the study in regular use of optimized doses of recommended medications to improve the survival and prevent adverse VR after MI (Table 1). This study was carried out in accordance with the declaration of Helsinki and was approved by the local ethics research committee. A signed informed consent was obtained from all patients studied.

\section{Cardiopulmonary exercise testing}

During exercise test a mouth piece connected to a valve allowed the expired gases to be measured with a CPX/D analyzer MedGraphics (Saint Paul, USA). The Software BreezeEX was used for acquisition, processing and storage of the cardiorespiratory variables. All patients were submitted to a modified Balke treadmill protocol, with fixed speed from the third stage and successive increments of $2 \%$ slope every minute thereafter. Continuous cardiac monitoring was performed by Mason-Likar deriving system modified with 13 derivations, and blood pressure measured manually every minute during the stress and recovery periods. All tests were conducted up to the intensity level in which the patient referred significant fatigue or dyspnea, and had reached a respiratory exchange ratio greater than 1.05 , that was used as a maximum exercise test criterion [10].

Table 1. Baseline characteristics, coronary artery reperfusion strategy and medications in use by patients

\begin{tabular}{|l|c|c|c|}
\hline & $\begin{array}{c}\text { Training group } \\
\mathbf{( N = 8 )}\end{array}$ & $\begin{array}{c}\text { Control group } \\
\mathbf{( N = 8 )}\end{array}$ & $*$ \\
\hline Gender $(\mathrm{M} / \mathrm{F})$ & $7 / 1$ & $6 / 2$ & - \\
Age $(\mathrm{y})$ & $54.1 \pm 12$ & $55.1 \pm 9$ & $\mathrm{p}>0.05$ \\
\hline Weight $(\mathrm{Kg})$ & $77.0 \pm 11$ & $75.8 \pm 13$ & $\mathrm{p}>0.05$ \\
\hline BMI $\left(\mathrm{Kg} / \mathrm{m}^{2}\right)$ & $27.2 \pm 5$ & $28.8 \pm 5$ & $\mathrm{p}>0.05$ \\
\hline MI Time (days) & $74 \pm 27$ & $102 \pm 44$ & $\mathrm{P}>0.05$ \\
\hline Treatment in acute phase & & & \\
\hline FT & $3 / 8$ & $4 / 8$ & \\
\hline Primary PCI & $2 / 8$ & $0 / 8$ & \\
\hline CT & $3 / 8$ & $4 / 8$ & \\
\hline Medication during protocol & & & \\
\hline ACEI/ARB & $8 / 8$ & $7 / 8$ & \\
\hline$\beta$-blockers & $8 / 8$ & $8 / 8$ & \\
\hline Antiplatelet & $8 / 8$ & $8 / 8$ & \\
\hline Statins & $8 / 8$ & $8 / 8$ & \\
\hline
\end{tabular}

Data are expressed as means $\pm \mathrm{SD}$ or number of patients. * Mann-Whitney's test, significance level of $5 \%(\mathrm{p}<0.05)$. BMI indicates body mass index; MI, myocardial infarction; FT, fibrinolytic therapy; primary PCI, primary percutaneous coronary intervention t; CT, clinical treatment, no reperfusion therapy; ACEI, angiotensin converting enzyme inhibitors; ARB, angiotensin receptor blockers

\section{Cardiac magnetic resonance}

Cardiac magnetic resonance imaging was carried out using MRI equipment - Achieva Phillips-Siemens-1.5 T (Erhlangen, Germany), with $25 \mathrm{mT}$ gradient coils, of circular polarization. After the images of heart localization, sequences were carried out for evaluating cardiac function. The sequence used was the rapid gradient echo with TRUE FISP state-balance acquisition with adjusted parameters in order to optimize the signal-to-noise ratio. Flip angle $=10$ degrees, slice thickness $=8 \mathrm{~mm}$; interval among slices $=0 \mathrm{~mm} ; 13$ phases of cardiac cycle in a single slice, after each respiratory apnea, always synchronized to the electrocardiogram signal. In doing so it was possible to obtain a film of the cardiac cycle with great temporal resolution and delineation of endocardium and epicardium (optimized spatial resolution). Images from the LV were obtained in short axis, in order to cover all the extension of LV (10 to 13 slices). Data using dedicated software were obtained for measurement of the following variables: end-diastolic volume (EDV), end-systolic volume (ESV), EF, cardiac output (CO) and LV mass; dedicated software Segment version 1.9 RXXXX (http:// segment.heiberg.se), based on Simpson's technique, was used to calculate EF.

\section{Neurohumoral assessment}

Neurohumoral status was evaluated through measurement of NT-proBNP plasma levels. Venous blood was sampled before and immediately after cardiopulmonary exercise testing through a venous catheter inserted in a large vein of the left upper limb, approximately 35 minutes before the cardiopulmonary exercise testing. Five minutes before starting the test a $5 \mathrm{~m}$ blood sample was collected, having the patient remained resting in a sitting position since the catheter insertion [11]. A second sample was collected immediately after the end of the cardiopulmonary exercise testing. Aliquots of plasma were stored $-80^{\circ} \mathrm{C}$ for NT-proBNP measurements, after centrifugation at $3,000 \mathrm{rpm}$ for $10 \mathrm{~min}$ at $4^{\circ} \mathrm{C}$. The NT-proBNP plasma concentration was measured through an immunoenzymatic method type sandwich, associated to a final stage of detection, through ELFA (Enzyme-Linked Fluorescent Assay) technique using kit Vida's ${ }^{\oplus}$ NT-proBNP (bioMérieux $S A)$.

\section{Aerobic training}

Patients selected for TG were submitted to 03 supervised sessions per week of aerobic exercise training, on treadmill, at the Rehabilitation Center of the Medical School of Ribeirao Preto of the University of Sao Paulo. The exercise training was of moderate intensity, set at a value close to the ventilatory anaerobic threshold [12], determined through the initial cardiopulmonary exercise testing. Target heart rate (HR) was calculated through direct method by plotting the heart rate versus the $\mathrm{VO}_{2}$ values, both having been measured simultaneously. Then, the minimum training heart rate (HR) was defined as the one reaching a value $10 \%$ below the anaerobic threshold, and the maximum heart rate as the one $10 \%$ above the anaerobic threshold. Training sessions included the following phases: warming up, lasting 05 minutes; conditioning, with load settings (speed and inclination) in order to maintain the HR within the training zone for 30 minutes; and recovery with duration of 05 minutes. During each training session, it was obtained the HR values continuously, using a cardio frequency device (Polar ${ }^{\circledR}$ FS1), and blood pressure by the auscultatory method, using an aneroid sphygmomanometer, at baseline, peak exertion and at the 5th minute of recovery. The Borg scale was used for the evaluation of perceived exertion during the training sessions. Patients in the CG were told to perform their usual activities of daily 
living. All patients were routinely followed at the outpatient cardiac rehabilitation clinic in our institution. The cardiac magnetic resonance imaging and the cardiopulmonary exercise testing with blood sampling for measurement of NT-proBNP were performed after 12 weeks of the follow up period.

\section{Statistical analysis}

Data are expressed as mean \pm SD. A p-value, less than 0.05 , was considered statistically significant. Based on the small sample size, the non-parametric tests were used for data analysis. The Wilcoxon's rank sum test was used for comparison of two paired samples. The MannWhitney's test was used for comparison of two non-paired samples.

The authors had full access to and take full responsibility for the integrity of the data. All authors have read and agreed to the manuscript content as written.

\section{Results}

\section{Parameters of cardiopulmonary exercise testing}

Comparative analysis between the groups, GC, and TG, did not disclose any statistically significant difference in the initial assessment of the parameters derived from the cardiopulmonary exercise testing.
In contrast to the CG, that showed no significant changes, the TG presented, after the period of 12 weeks of the aerobic exercise training, an increase, with statistical significance, in $\mathrm{VO}_{2}$ peak from $19.3 \pm 4.0$ to $22.4 \pm 4.5 \mathrm{ml} \cdot \mathrm{kg}^{-1} \cdot \mathrm{min}^{-1}(\mathrm{p}<0.05)$, and in $\mathrm{VO}_{2}$ at AT from $11.6 \pm 1.9$ to $13.2 \pm 2.6 \mathrm{ml} \cdot \mathrm{kg}^{-1} \cdot \mathrm{min}^{-1}(\mathrm{p}<0.05)$ (Table 2). The calculated increase in $\mathrm{O}_{2}$ pulse, from rest to peak exercise, expressed as $\Delta \mathrm{O}_{2}$ pulse, also had a different behavior in the two groups. There was a statistically significant increase in the $\Delta \mathrm{O}_{2}$ pulse of the TG $(6.4 \pm 1.2$ to $8.1 \pm 1.7 ; \mathrm{p}<0.05)$, with no significant change in the CG $(7.0 \pm 2.3$ to $6.9 \pm 3.0$; $p>0.05)$ (Figure 1).

\section{Parameters of cardiac magnetic resonance}

Comparative analysis between the groups did not show statistically significant differences in the initial assessment of the cardiac magnetic resonance parameters. In the TG, there were no significant changes in LVEDV (156.7 \pm 47.3 to $145.4 \pm 42.0 \mathrm{ml} \mathrm{p}>0.05)$, in LVESV (93.7 \pm 33.8 to $84.3 \pm 35.4 \mathrm{ml} \mathrm{p}>0.05)$ and LV mass (132.5 \pm 36.3 to 136.9 $\pm 36.1 \mathrm{~g} \mathrm{p}>0.05)$. In the CG, there was a significant LVEDV decrease from $170.1 \pm 30.1$ to $156.8 \pm 32.5 \mathrm{ml}(\mathrm{p}<0.05)$ but no significant LVESV change $(104.5 \pm 28.4$ to $94.1 \pm 35.9 \mathrm{ml} \mathrm{p}>0.05)$ and LV mass $(126.0 \pm$ 28.5 to $141.9 \pm 32.7 \mathrm{~g} \mathrm{p}>0.05$ ) (Table 3 ). When the ratio of LV mass to end-diastolic volume (LV mass/EDV) was calculated, it was observed an increase in LV mass/EDV ratio from $0.74 \pm 0.19$ to $0.94 \pm 0.31$ g. $\mathrm{ml}^{-1}$

Table 2. Cardiopulmonary exercise testing parameters.

\begin{tabular}{|c|c|c|c|c|c|c|}
\hline & \multicolumn{3}{|c|}{ Training group $(\mathrm{N}=8)$} & \multicolumn{3}{|c|}{ Control group $(\mathrm{N}=8)$} \\
\hline & Baseline & Follow-Up & $*$ & Baseline & Follow-Up & $*$ \\
\hline $\mathrm{VO}_{2}$ peak $\left(\mathrm{ml} \cdot \mathrm{kg}^{-1} \cdot \mathrm{min}^{-1}\right)$ & $19.3 \pm 4.0$ & $22.4 \pm 4.5$ & $\mathrm{p}<0.05$ & $18.9 \pm 4.8$ & $17.6 \pm 5.1$ & $\mathrm{p}>0.05$ \\
\hline $\mathrm{VO}_{2} \mathrm{AT}\left(\mathrm{ml} \cdot \mathrm{kg}^{-1} \cdot \mathrm{min}^{-1}\right)$ & $11.6 \pm 1.9$ & $13.2 \pm 2.6$ & $\mathrm{p}<0.05$ & $13.6 \pm 2.8$ & $12.1 \pm 3.4$ & $\mathrm{P}>0.05$ \\
\hline VE (L.min $\left.{ }^{-1}\right)$ & $63.5 \pm 11.5$ & $71.2 \pm 12.1$ & $\mathrm{p}>0.05$ & $59.2 \pm 18.1$ & $50.5 \pm 17.4$ & $\mathrm{p}<0.05$ \\
\hline $\mathrm{O}_{2 \text { pulse }}$ at rest $\left(\mathrm{ml}\right.$. systole $\left.^{-1}\right)$ & $4.9 \pm 1.5$ & $4.4 \pm 0.9$ & $\mathrm{p}>0.05$ & $4.5 \pm 1.2$ & $4.1 \pm 0.8$ & $\mathrm{P}>0.05$ \\
\hline $\mathrm{O}_{2}$ pulse peak (ml. systole $\left.{ }^{-1}\right)$ & $11.3 \pm 1.0$ & $12.5 \pm 1.9$ & $\mathrm{p}>0.05$ & $11.5 \pm 3.1$ & $11.1 \pm 3.1$ & $\mathrm{p}>0.05$ \\
\hline$\Delta \mathbf{O}_{2}$ pulse & $6.4 \pm 1.2$ & $8.1 \pm 1.7$ & $\mathrm{P}<0.05$ & $7.0 \pm 2.3$ & $6.9 \pm 3.0$ & $\mathrm{p}>0.05$ \\
\hline RER & $1.14 \pm 0.07$ & $1.19 \pm 0.08$ & $\mathrm{P}<0.05$ & $1.07 \pm 0.02$ & $1.08 \pm 0.01$ & $\mathrm{p}>0.05$ \\
\hline HR at rest (bpm) & $64.2 \pm 13.0$ & $64.1 \pm 8.5$ & $\mathrm{p}>0.05$ & $66.3 \pm 13.4$ & $66.6 \pm 6.8$ & $\mathrm{p}>0.05$ \\
\hline HR peak (bpm) & $134.5 \pm 12.1$ & $132.0 \pm 19.3$ & $\mathrm{p}>0.05$ & $128.7 \pm 23.9$ & $127.3 \pm 25.4$ & $\mathrm{p}>0.05$ \\
\hline SBP peak(mmHg) & $150.6 \pm 22.1$ & $148.1 \pm 15.3$ & $\mathrm{p}>0.05$ & $156.2 \pm 20.1$ & $153.1 \pm 8.40$ & $\mathrm{p}>0.05$ \\
\hline RPP (bpm. mmHg ${ }^{-1}$ ) & $20411 \pm 4357$ & $19854 \pm 4464$ & $\mathrm{p}>0.05$ & $20159 \pm 4475$ & $19413 \pm 3394$ & $\mathrm{p}>0.05$ \\
\hline
\end{tabular}

Data are expressed as means \pm SD. * Wilcoxon's rank sum test, significance level of $5 \%(\mathrm{p}<0.05)$. VO indicates oxygen uptake; AT, ventilatory anaerobic threshold; VE, minute ventilation; $\Delta \mathrm{O}_{2}$ pulse, increase of $\mathrm{O}_{2}$ pulse from rest to peak; RER, respiratory exchange ratio; HR, heart rate; SBP, systolic blood pressure; RPP, rate-pressure product.

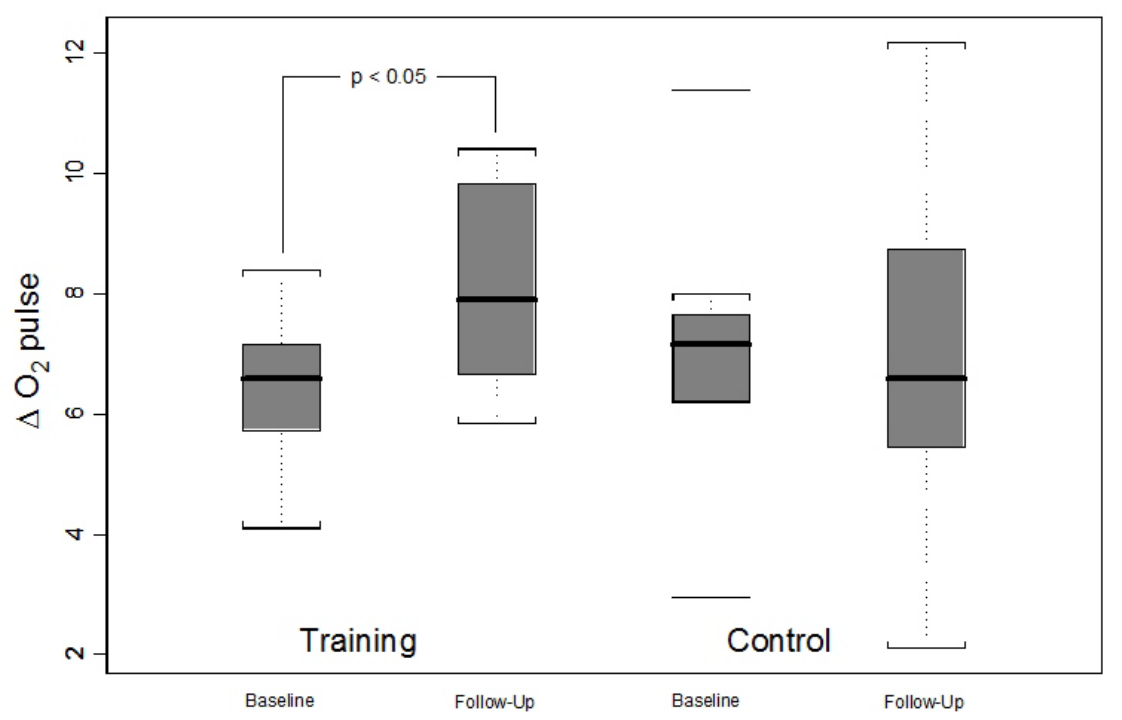

Figure 1. Analysis of $\Delta \mathrm{O}_{2}$ pulse response between training and control groups before and after the interventions. 
Table 3. Cardiac magnetic resonance parameters.

\begin{tabular}{|c|c|c|c|c|c|c|}
\hline & \multicolumn{3}{|c|}{ Training group $(\mathrm{N}=8)$} & \multicolumn{3}{|c|}{ Control group $(\mathrm{N}=8)$} \\
\hline & Baseline & Follow-Up & $*$ & Baseline & Follow-Up & $*$ \\
\hline LVEDV (ml) & $156.7 \pm 47.3$ & $145.4 \pm 42.0$ & $\mathrm{p}>0.05$ & $170.1 \pm 30.1$ & $156.8 \pm 32.5$ & $\mathrm{p}<0.05$ \\
\hline LVESV (ml) & $93.7 \pm 33.8$ & $84.3 \pm 35.4$ & $\mathrm{p}>0.05$ & $104.5 \pm 28.4$ & $94.1 \pm 35.9$ & $\mathrm{p}>0.05$ \\
\hline LVEF (\%) & $40.7 \pm 5.6$ & $43.5 \pm 6.7$ & $\mathrm{p}>0.05$ & $39.7 \pm 8.3$ & $41.7 \pm 13.2$ & $\mathrm{p}>0.05$ \\
\hline LVSV (ml) & $62.8 \pm 16.3$ & $61.0 \pm 9.0$ & $\mathrm{p}>0.05$ & $65.5 \pm 14.2$ & $63.2 \pm 15.7$ & $\mathrm{p}>0.05$ \\
\hline LVCO $\left(1 . \mathrm{min}^{-1}\right)$ & $4.0 \pm 1.1$ & $3.9 \pm 0.9$ & $\mathrm{p}>0.05$ & $4.2 \pm 0.9$ & $4.2 \pm 1.0$ & $\mathrm{p}>0.05$ \\
\hline LV mass (g) & $132.5 \pm 36.3$ & $136.9 \pm 36.1$ & $\mathrm{p}>0.05$ & $126.0 \pm 28.5$ & $141.9 \pm 32.7$ & $\mathrm{p}>0.05$ \\
\hline LV mass/EDV (g.ml $\left.{ }^{-1}\right)$ & $0.89 \pm 0.33$ & $0.96 \pm 0.26$ & $\mathrm{p}>0.05$ & $0.74 \pm 0.19$ & $0.94 \pm 0.31$ & $\mathrm{P}<0.05$ \\
\hline
\end{tabular}

Data are expressed as means \pm SD. * Wilcoxon's rank sum test, significance level of $5 \%$ ( $<<0.05)$. LVEDV indicates LV end-diastolic volume; LVESV, LV end-systolic volume; LVEF, LV ejection fraction; LVSV, LV stroke volume; LVCO, LV cardiac output.

Table 4. Values of NT-proBNP plasma levels at rest and peak exercise conditions.

\begin{tabular}{|c|c|c|c|c|c|c|}
\hline & \multicolumn{3}{|c|}{ Training group $(\mathrm{N}=8)$} & \multicolumn{3}{|c|}{ Control group $(\mathrm{N}=8)$} \\
\hline & Baseline & Follow-Up & $*$ & Baseline & Follow-Up & $*$ \\
\hline NT-proBNP at rest (pg.ml ${ }^{-1}$ ) & $947 \pm 382$ & $474 \pm 216$ & $\mathrm{p}<0.05$ & $833 \pm 444$ & $456 \pm 285$ & $\mathrm{p}<0.05$ \\
\hline $\begin{array}{l}\text { NT-proBNP peak } \\
\left(\text { pg.ml }{ }^{-1}\right)\end{array}$ & $1081 \pm 430$ & $566 \pm 262$ & $\mathrm{p}<0.05$ & $956 \pm 529$ & $542 \pm 406$ & $\mathrm{p}<0.05$ \\
\hline$\Delta$ NT-proBNP & $133 \pm 71$ & $91 \pm 55$ & $\mathrm{p}>0.05$ & $122 \pm 94$ & $86 \pm 126$ & $\mathrm{p}>0.05$ \\
\hline
\end{tabular}

Data are expressed as means \pm SD. * Wilcoxon's rank sum test, significance level of $5 \%(\mathrm{p}<0.05) . \Delta$ NT-proBNP indicates increase of NT-proBNP from rest to peak.

$(\mathrm{p}<0.05)$ in the CG, and no significant change in the TG from $0.89 \pm$ 0.33 to $0.96 \pm 0.26$ g.ml- ${ }^{-1}(\mathrm{p}>0.05)$ (Figure 2).

No significant changes occurred in the LVEF measured in the follow-up in both groups, from baseline to end of follow-up the LVEF values were: in the TG $40.7 \pm 5.6$ to $43.5 \pm 6.7 \%(\mathrm{p}>0.05)$ and in the CG $39.7 \pm 8.3$ to $41.7 \pm 13.2 \%$ ( $>0.05)$ (Table 3$)$. Also, cardiac output values were comparable in the two groups at baseline and had no significant changes after the follow-up period.

\section{NT-proBNP plasma levels}

Comparative analysis between the two groups, did not present statistically significant differences in the initial assessment of NTproBNP plasma levels at rest and peak exercise conditions. In the follow-up evaluation, there was a statistically significant decrease of NT-proBNP plasma levels at rest and peak exercise conditions in both groups. From baseline to follow-up in TG, NT-proBNP at rest decreased from $947 \pm 382$ to $474 \pm 216$ pg.ml ${ }^{-1}(\mathrm{p}<0.05)$, and in peak exercise it decreased from $1081 \pm 430$ to $566 \pm 262 \mathrm{pg} \cdot \mathrm{ml}^{-1}(\mathrm{p}<0.05)$. Similarly, in CG, NT-proBNP at rest decreased from $833 \pm 444$ to $456 \pm 285$ pg. $\mathrm{ml}^{-1}$ $(\mathrm{p}<0.05)$, and in peak exercise it decreased from $956 \pm 529$ to $542 \pm 406$ pg. $\mathrm{ml}^{-1}(\mathrm{p}<0.05)$. There were no statistically significant changes in the observed NT-proBNP increases from rest to peak exercise, expressed as $\triangle \mathrm{NT}$-proBNP, comparing pre-versus post-12-week evaluations, in either TG or CG (Table 4).

\section{Discussion}

Over the last decades several scientific works were published, which sought to assess the effects of the aerobic physical exercise on VR and the cardiac function of patients suffering from MI, who evolved with LV systolic dysfunction [7-10,13-16]. Many of these studies, considered classics and pioneers, continue to be cited in various scientific articles and are selected for composing meta-analyses, despite having been conducted at a time when blocking of neurohumoral activation after MI was not understood as the cornerstone of the treatment of ventricular dysfunction. In contrast to most of those studies, almost all patients included in our study were in regular and optimized use of beta-blockers and inhibitors of ACEI $[9,14]$. Improvement of physical and cardiorespiratory fitness is an expression of the increase

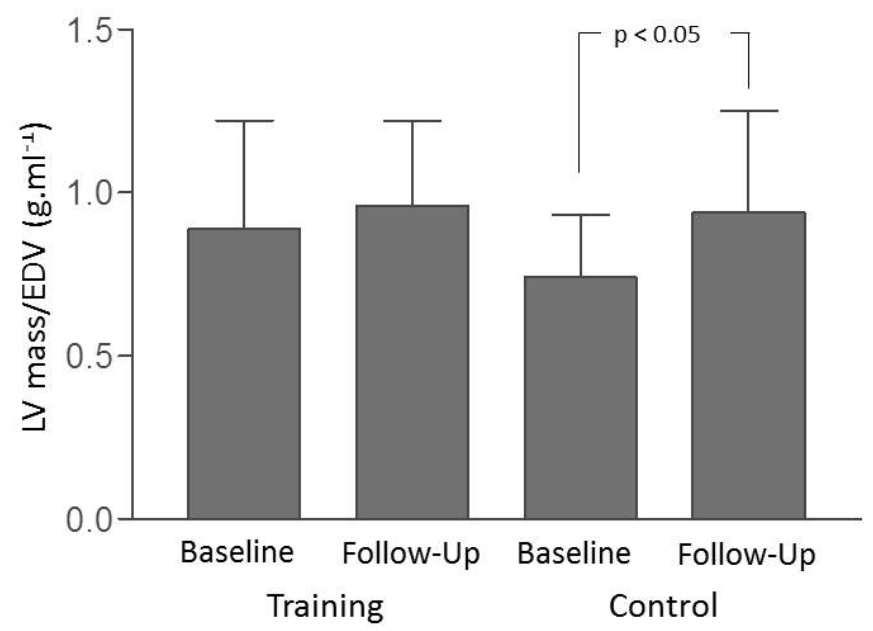

Figure 2. Analysis of the LV mass/EDV ratio between the training and control groups before and after the interventions.

of $\mathrm{VO}_{2}$ peak that is a desirable adaptation for patients with $\mathrm{MI}$ and ventricular dysfunction engaged in aerobic training. It is considered the most important predictor of morbimortality, comparatively to other risk factors established for cardiovascular diseases, as showed in a study conducted by Myers et al [17].

Data of aerobic improvement found in this study are comparable to those described in literature, where percentage increases of $\mathrm{VO}_{2}$ between 10 and $30 \%$ are reported [18]. In this present study, it was observed a percentage increase of $\mathrm{VO}_{2}$ peak of $16 \%$ after applying moderate-intensity aerobic physical exercise. The $\mathrm{O}_{2}$ pulse bears a close relationship with LV cardiac output, being considered an additional parameter of systolic performance [19]. Giallauria et al [20]. showed a significant improvement in $\mathrm{O} 2$ pulse for a group of patients with recent MI enrolled in an exercise-based cardiac rehabilitation program. Regarding the data of this study, the $\Delta \mathrm{O} 2$ pulse indicates an improvement of the LV systolic performance during dynamic physical effort in the TG. Among several papers from the literature, Giannuzzi et al [8]. showed an increase in cardiac function and maintenance of chamber volumes. Kubo et al [9]. observed an increase of chamber 
volumes, but maintenance of cardiac function with physical activity prescription around the third week after the event. Giallauria et al [21]. showed both maintenance of cardiac chamber volumes and function. According to Dubach et al [7]., discrepancies among those several studies could be attributed to factors related to heterogeneity of samples, differences of training intensity, diversity of methodology used in the calculation of chamber volume measurements and ventricular function in VR assessment, or even a combination of these factors. In order to maximize the accuracy in chamber volume measurements, ventricular mass and estimation of cardiac function, in our study a magnetic resonance imaging study was carried out, which provides higher accuracy compared to other imaging methods. This selected methodology reduces the need for sample size for intervention studies, in addition to providing reliable assessment for individual cases [22-24]. In the present study, we observed the maintenance of the chamber volumes and of the LV function with the aerobic training of moderate intensity. Fargard [25] postulates that the intermittent volume overload, promoted by aerobic exercise training, can lead to propitiate the appearance of eccentric ventricular hypertrophy. This effect could explain the absence of decrease of the chamber volumes in the TG, notably of the EDV, in comparison with the decrease observed in the CG.

The ratio of LV mass to end-diastolic volume (LV mass/EDV) is closely related to the relative wall thickness. It is a parameter that can be used to define the patterns of LV remodeling and geometry. An increase of LV mass/EDV indicates the development of concentric geometry [26]. Verma et al [27]. showed that LV concentric geometry was associated with increased risk of cardiovascular adverse events in post-MI patients. In our study, the behavior of the LV mass/EDV suggests that aerobic exercise training has a protective effect over the spontaneous process of LV concentric remodeling exhibited by the CG as compared to the TG. It is known that plasma levels of natriuretic peptides increase after MI, and several authors have studied the impact of aerobic training in type B Natriuretic Peptide (BNP) secretion in an after-MI context. Yamamoto et al [16]. and Wisløff et al [10]. did not observed changes of BNP and proBNP plasma levels, after aerobic training of moderate intensity. Giallauria et al $[21,28]$, showed a decrease of NT-proBNP circulating levels after three months of moderateintensity aerobic training, in patients with ventricular dysfunction after MI. Our data show that moderate-intensity aerobic training does not interfere with the natural course of NT-proBNP plasma level decrease, which usually occurs in the context of MI, associated to VR, as reported by Nagaya et al [29].

In summary, the overall behavior of several parameters in both groups shows that a moderate-intensity aerobic training caused an increase in physical and cardiorespiratory reserve, maintenance of cardiac chamber volumes and of LV function, as well as a normal neurohumoral response in selected post-infarction patients.

\section{Study limitations}

It was established a rigid inclusion criteria for the study of patients in the post-MI context, what reflected in a relatively small sample; however, it also resulted in a homogeneous sample, related to the age, anthropometric characteristics, modality, and topography of MI, as well as the time elapsed between MI and the inclusion in the study. Patients were included between the $5^{\text {th }}$ and $24^{\text {th }}$ weeks after MI, and the aerobic training period was 12 weeks. In recent meta-analysis, Haykowsky et al [30]. suggested largest benefits in aerobic training programs with early onset and prolonged duration. Finally, in our study we did not assess the presence of myocardial viability in the infarct area. Its presence might represent an important determinant of the results of physical training.

\section{Conclusion}

Aerobic exercise training seems to have a protective effect over the spontaneous process of LV concentric remodeling in the context of post-myocardial infarction patients, and it promotes an improvement of the LV systolic performance during dynamic physical effort, without triggering adverse neurohumoral activation.

\section{Funding}

Research supported by FAEPA HCFMRP-USP, FAPESP.

\section{Conflicts of interest}

The authors have no conflicts of interest to declare.

\section{References}

1. Cohn JN, Ferrari R, Sharpe N (2000) Cardiac remodeling--concepts and clinica implications: a consensus paper from an international forum on cardiac remodeling. Behalf of an International Forum on Cardiac Remodeling. J Am Coll Cardiol 35: 569582. [Crossref]

2. Sutto MG, Sharpe N. (2000) Left ventricular remodeling after myocardial infarction: Pathophysiology and Therapy. Circulation 101:2981-2988. [Crossref]

3. Chareonthaitawee P, Christian TF, Hirose K, Gibbsons RJ, Rumberger JA. (1995) Relation of initial infarct size to extent of left ventricular remodeling in the year after acute myocardial infarction. J Am Coll Cardiol 25:567-573. [Crossref]

4. Middlekauff HR, Mark AL (1998) The treatment of heart failure: the role of neurohumoral activation. Intern Med 37: 112-122. [Crossref]

5. Packer M (1992) The neurohormonal hypothesis: a theory to explain the mechanism of disease progression in heart failure. $J$ Am Coll Cardiol 20: 248-254. [Crossref]

6. Antonopoulos GV, Lau J, Konstam MA, Udelson JE. (1999) Are drug-induced changes in left ventricular ejection fraction or volumes adequate surrogates for long-term natural history outcomes in heart failure? Circulation 100: 1296.

7. Dubach P, Myers J, Dziekan G, Goebbels U, Reinhart W, et al. (1997) Effect of exercise training on myocardial remodeling in patients with reduced left ventricular function after myocardial infarction: application of magnetic resonance imaging. Circulation 95:2060-2067. [Crossref]

8. Giannuzzi P, Temporelli PL, Corra U, Gattone M, Giordano A, et al. (1997) For the ELVD Study Group. Attenuation of unfavorable remodeling by exercise training in post infarction patients with left ventricular dysfunction. Circulation 96:1790-1797. [Crossref]

9. Kubo N, Ohmura N, Nakada I, et al. (2004) Exercise at ventilatory threshold aggravates left ventricular remodeling in patients with extensive anterior acute myocardial infarction. Am J Cardiol 147:113-120.

10. Wisløff U, Støylen A, Loennechen JP, Bruvold M, Rognmo Ø, et al. (2007) Superior cardiovascular effect of aerobic Interval training versus moderate continuous training in heart failure patients: a randomized study. Circulation 115:3086-3094. [Crossref]

11. Boomsma F, van den Meiracker AH (2001) Plasma A- and B-type natriuretic peptides physiology, methodology and clinical use. Cardiovasc Res 51: 442-449. [Crossref]

12. Wasserman K, Whipp BJ, Koyl SN, Beaver WL (1973) Anaerobic threshold and respiratory gas exchange during exercise. J Appl Physiol 35: 236-243. [Crossref]

13. Jugdutt BI, Michorowski BL, Kappagoda CT. (1988) Exercise training after anterior $\mathrm{Q}$ wave myocardial infarction: Importance of regional left ventricular function and tomography. J Am Coll Cardiol 12:362-372. [Crossref]

14. Jetté M, Heller R, Landry F, Blümchen G (1991) Randomized 4-week exercise program in patients with impaired left ventricular function. Circulation 84: 1561-1567. [Crossref]

15. Giannuzzi P, Tavazzi L, Temporelli PL, Corrà U, Imparato A, et al. (1993) Long-term physical training and left ventricular remodeling after anterior myocardial infarction: results of the Exercise in Anterior Myocardial Infarction (EAMI) trial. EAMI Study Group. J Am Coll Cardiol 22:1821-1829. [Crossref] 
16. Yamamoto A, Tanabe K, Yokoyama Y, Itoh H, Murayama M. (1998) Influence of aerobic exercise training on brain natriuretic peptide secretion in patients in the chronic phase of myocardial infarction. Jpn Circ J 62: 658-664. [croossref]

17. Myers J, Prakash M, Froelicher V, Do D, Partington S, et al. (2002) Exercise capacity and mortality among men referred for exercise testing. $N$ Engl J Med 346: 793-801. [Crossref]

18. Valkeinen H, Aaltonen S, Kujala UM (2010) Effects of exercise training on oxygen uptake in coronary heart disease: a systematic review and meta-analysis. Scand J Med Sci Sports 20: 545-555. [Crossref]

19. American Thoracic Society; American College of Chest Physicians (2003) ATS/ACCP Statement on cardiopulmonary exercise testing. Am J Respir Crit Care Med 167: 211 277. [Crossref]

20. Giallauria F, Acampa W, Ricci F, Vitelli A, Maresca L, et al. (2012) Effects of exercise training started within 2 weeks after acute myocardial infarction on myocardial perfusion and left ventricular function: a gated SPECT imaging study. Eur J Prev Cardiol 19(6):1410-1419. [Crossref]

21. Giallauria F, De Lorenzo A, Pilerci F, et al. (2006) Reduction of N terminal-pro-brain (B-type) natriuretic peptide levels with exercise-based cardiac rehabilitation in patientes with left ventricular dysfunction after myocardial infarction. Eur J Cardiovasc Prev Rehabil 13(4):625-632. [Crossref]

22. Buser PT, Auffermann W, Holt WW, Wagner S, Kircher B, et al. (1989) Noninvasive evaluation of global left ventricular function with use of cine nuclear magnetic resonance. J Am Coll Cardiol 13: 1294-1300. [Crossref]
23. Cowan BR, Young AA. (1998) Regional analysis of left ventricular motion after myocardial infarction. Proc Int Soc Magn Reson 2:884.

24. Pennel DJ, Sechtem UP, Higgins CB, Manning WJ, Pohost GM, et al. (2004) Clinical indications for cardiovascular magnetic resonance (CMR): Consensus Panel report. Eur Heart J 25:1940-1965. [Crossref]

25. Fagard R (2003) Athlete's heart. Heart 89: 1455-1461. [Crossref]

26. Gaasch WH, Zile MR (2011) Left ventricular structural remodeling in health and disease: with special emphasis on volume, mass, and geometry. J Am Coll Cardiol 58: 1733-1740. [Crossref]

27. Verma A, Meris A, Skali H, Ghali JK, Arnold JM, et al. (2008) Prognostic implications of left ventricular mass and geometry following myocardial infarction: the VALIANT (VALsartan in Acute myocardial iNfarcTion) Echocardiographic Study. JACC Cardiovasc Imaging 1: 582-591. [Crossref]

28. Giallauria F, Cirillo P, Lucci R, Pacileo M, De Lorenzo A, et al. (2008) Left ventricula remodelling in patients with moderate systolic dysfunction after myocardial infarction favourable effects of exercise training and predictive role of N-terminal pro-brain natriuretic peptide. Eur J Cardiovasc Prev Rehabil 15:113-118. [Crossref]

29. Nagaya N, Goto Y, Nishikimi T, et al. (1999) Sustained elevation of plasma brain natriuretic peptide levels associated with progressive ventricular remodelling after acute myocardial infarction. Clin Sci 96(2):129-136.

30. Haykowsky M, Scott J, Esch B, Schopflocher D, Myers J, et al. (2011) A meta-analysis of the effects of exercise training on left ventricular remodeling following myocardia infarction: start early and go longer for greatest exercise benefits on remodeling. Trials 12: 92 . [Crossref]

Copyright: (C2017 Santi GLD. This is an open-access article distributed under the terms of the Creative Commons Attribution License, which permits unrestricted use, distribution, and reproduction in any medium, provided the original author and source are credited. 